\title{
Binary-choice sequences of retardates, normal children, and college students under random- and pattern-set instructions'
}

Irma R. Gerjuoy, JOHNSTONE TRAINING AND RESEARCH CENTER, BORDENTOWN, N. J. Herbert Gerjuoy, EDUCATIONAL TESTING SERVCE

\begin{abstract}
In twenty nonreinforced binary choices, adolescent retardates, normal children, and college students gave no more alternations when instructed to respond randomly than when instructed to respond with a simple pattern. These results imply that alternation above chance is due to something other than preconceptions about the nature of random sequences.

\section{Problem}

There is a rather broadly observed tendency of Ss to give binary-choice sequences rich in alternations (Bakan, 1960; Brown, 1964; H. Gerjuoy \& I. R. Gerjuoy, 1964; Iwahara, 1959; Ross \& Levy, 1958; Yacorzynski, 1941). This may or may not be a consequence of preconceptions about the nature of random sequences (Reichenbach, 1949, p. 153). The present study was concerned with binary-choice sequences elicited from retardates, normal children, and college students under one of two different sets of instructions: to generate a $\mathrm{r}$ andom sequence of choices or to generate a patterned sequence. If pattern-set instructions elicit as much as or more alternation than random-set instructions, then alternation under random-set instructions ought not be attributed to the mention of randomness.
\end{abstract}

\section{Subjeets}

The Ss were 100 fourth- and fifth-grade normal children, 1027 college students, and 110 institutionalized adolescent educable mental retardates.

\section{Stimulus Materials}

The stimulus materials consisted of three columns on a sheet of paper: The column on the left contained the numerals 1 to 20 , the middle column contained 20 letter A's, and the column on the right contained 20 letter B's.

\section{Procedure}

All Ss were tested in groups. The instructions are presented in full in I. R. Gerjuoy \& H. Gerjuoy, 1964. College students were told that this was an ESP experiment. The random-set groups were instructed that a coin had been tossed to preselect randomly one letter, either A or B, as the correct letter for each choice and that the other letter was wrong for that choice. They were instructed to guess the order in which the heads and tails came up that determined whether A or B was correct, and they were advised that their choices should be scattered randomly. The pattern-set groups were given similar instructions but were told to respond with a simple pattern. The retardates and the normal children were given instructions that paralleled those given the college Ss but that used simpler language.

\section{Response Measures}

For each population under each instructional condition, the following response measures were tabulated: (a) whether there was alternation ( $A B$ or $B A$ ) or perseveration (AA or $\mathrm{BB}$ ) on the first two choices, (b) the overall proportion of alternation for all 20 choices, (c) whether the choice-sequence pattern was cyclic (the same choice-sequence pattern repeated throughout the 20 choices, e. g., ABBABBABBABBABBA $\mathrm{BBAB}$ ), and, if it was cyclic, (d) the cycle length (the number -1 to 10 -of letters in the repeated pattern, e. g., 3 for $\mathrm{ABB}$ in the preceding example).

\section{Results}

On the first two choices, all groups alternated above chance except for the college Ss under random-set instructions. Among both normal children and college students, alternation was much greater under patternset instructions (see Table 1); among retardates, however, the amount of alternation was not influenced by instructions.

Alternation over the entire 20 choices was above chance for all combinations of instructional condition and $\mathrm{S}$ population. The adult Ss alternated less than the other groups. Only for the normal children did instructions affect the overall amount of alternation: the normal children alternated more under pattern-set instructions (see Table 1).

About $38 \%$ of the retardates gave cyclic-response sequence under both instructional conditions. Cyclic sequence percentages for normal children were 4 under

Table 1. Proportion of Alternations in the First Two Choices and in All Twenty Choices

\begin{tabular}{lrrr} 
& \multicolumn{3}{c}{ Choices } \\
$\begin{array}{lrrr}\text { Group } \\
\text { Pattern-set }\end{array}$ & $\mathrm{N}$ & 1 st 2 & All 20 \\
Retardates & 59 & .763 & .702 \\
Normal children & 53 & .868 & .766 \\
ollege students & 651 & .561 & .637 \\
Random-set & & & \\
etardates & & & \\
ormal children & 51 & .726 & .715 \\
ollege students & 376 & .553 & .646 \\
& & .380 & .610
\end{tabular}


random-set and 30 under pattern-set instructions; the corresponding percentages for college students were 1 and 69.

Among Ss who gave cyclic-response sequences, the mean cycle length depended on the population, with college students giving longer cycles than the other two groups. The most popular response sequence for retardates was single alternation, given by $27 \mathrm{Ss}$ in this population; the second most popular pattern for retardates was perseveration, given by $12 \mathrm{Ss}$. Only two of the normal children gave cyclic patterns other than single alternation. On the other hand, only $23 \%$ of the college students who gave cyclic patterns gave the single-alternation pattern. For college students, choice sequences with three- and four-choice cycles were as popular as single alternation. Of their cyclic-choice sequences, $29 \%$ contained five- to ten-choice cycles (completely absent in the other S groups), and only $71 \%$ of their cyclic sequences consisted of two-, three-, or four-choice cycles.

Frequency distributions were made of the number of alternations over all 20 choices under the two instructional conditions for the college Ss. The distribution under random-set instructions resembled a normal distribution; the distribution under pattern-set instructions was trimodal, reflecting the popularity of twochoice cycles (containing 19 alternations), three-choice cycles (12 or 13 alternations), and four-choice cycles (9 or 10 alternations).

\section{Diseussion}

Instructions to respond with a simple pattern produced as much alternation as did instructions to respond randomly. In fact, the normal children alternated more under the pattern-set instruction. Consequently, alternation does not appear to depend merely on preconceptions about randomness; on the contrary, instructions to respond randomly may actually reduce the amount of alternation by discouraging Ss from persisting with the simple, regular pattern of single alternation.

Pattern-set instructions elicited from college students complex, long-cycle patterns not given by lowerMA Ss. Thus, it seems that the college students' patterned binary-choice sequences took into account data from more of the preceding choices than did the sequences given by the lower-MA Ss. The college students' relatively long cycles, which were given despite instructions to give a simple pattern, may reflect their interpretation of "simple" as referring to more complexity than does the interpretation of "simple" by less sophisticated Ss.

\section{References}

BAKAN, P. Response-tendencies in attempts to generate random binary series. Amer. J. Psychol., 1960, 73, 127-131.

BROWN, D. L. Non-independence in subjectively random binary sequences. Research Bulletin 64-27. Princeton, N. J.: Educational Testing Service, 1964. (Multilithed report)

GERJUOY, H., \& GERJUOY, I. R. Choice-sequence patterns in binary choice "learning" by retardates. Amer. J. ment. Defic., 1964, 75-80.

GERJUOY, I. R., \& GERJUOY, H. Binary-choice sequences of retardates, normal children, and college students under randomand pattern-set instructions. Res. Bull., 64-45. Princeton, N. J.: Educational Testing Service, 1964. (Multilithed report)

IWAHARA, S. Studies in spontaneous alternation in human subjects. III. A developmental study. Jap. psychol. Res., 1959, 1, 1-8. REICHENBACH, $H$. 'The theory of probability: An inquiry into the logical and mathematical foundations of the calculus of probability (2nd ed.) Berkeley: Univer. Calif. Press, 1949.

ROSS, B. M., \& LEVY, N. Pattern predictions of chance events by children and adults. Psychol. Rep., 1958, 4, 87-124 (Monogr. Suppl. 1)

YACORZYNSKI, G. K. Perceptual principles involved in the disintegration of a configuration formed in predicting the occurrence of patterns selected by chance. J. exp. Psychol., 1941, 29, 401-406. Note

1. This report is based on a paper read at the Midwest. Psychol. Ass., St. Louis, May, 1964. We thank Sydell T. Carlton for editorial advice; Norman Wexler for help in analyzing data; and Ross Evans, Jr., Robert J. Greene, Kenneth W. Haun, R. J. Stierhem, John J. Winters, Jr., and the staff of the Department of Psychology of The University of Toledo for help in collecting data. 